\title{
POSTURAL PROFILE OF PATIENTS WITH HAM/TSP: COMPUTERIZED AND BAROPODOMETRIC ASSESSMENT
}

\author{
Edelvita Fernanda Duarte Cunha \\ Bahiana School of Medicine and \\ Public Health, Salvador, Bahia, Brazil. \\ Naiane Araújo Patrício \\ Bahiana School of Medicine and \\ Public Health, Salvador, Bahia, Brazil. \\ Maíra Carvalho Macedo \\ Bahiana School of Medicine and \\ Public Health, Salvador, Bahia, Brazil. \\ Fundação de Neurologia e Neurocirurgia \\ Instituto do Cérebro, Salvador, Bahia, \\ Brazil. \\ Cristiano Sena \\ Centro Universitário da Bahia, Salvador, \\ Bahia, Brazil. \\ Ramon Kruschewsky \\ Bahiana School of Medicine and Public \\ Health, Salvador, Bahia, Brazil . \\ Bernardo Galvão Castro Filho \\ Bahiana School of Medicine and \\ Public Health, Salvador, Bahia, Brazil. \\ Oswaldo Cruz Foundation, Salvador, \\ Bahia, Brazil. \\ Katia Nunes Sá PhD, Postgraduation Department, \\ Medicine and Public Health, Salvador, \\ Bahia, Brazil.
}

\begin{abstract}
Background: The HTLV-1 was the first retrovirus-associated with disease in human, being mainly associated with adult T-cell leukemia/lymphoma (ATLL) and tropical spastic paraparesis/HTLV-1-associated myelopathy (TSP/HAM). In the predominant clinical condition of HAM/TSP, biomechanical, sensory and functional alterations are observed. Objective: To describe and correlate postural deviations and the type of predominant weight load. Methods: This is a cross-sectional descriptive study, conducted with patients at the Center for HTLV, Salvador - Bahia. Data collection was performed in two steps, first evaluating postural orthostatic through digital photos of the individual, following the protocol SAPO ${ }^{\circledR}$ to mark anatomical points, the second step was the Baropodometric evaluation. For correlation of weight load and postural changes we used Pearson or Spearman correlation tests $(\alpha<0.05)$. Results: We studied 31 individuals, predominantly female $(54.8 \%)$, african descent $(58.1 \%)$, with a mean age of $52.8(+9.89)$ years. Analysis showed a predominance by an anteriorized position of the head $(80.6 \%)$, trunk displaced posteriorly $(64.5 \%)$, anteriorized body $(96,8 \%)$, hip extension $(77.4 \%)$, pelvic retroversion $(61.3 \%)$, flexed knee $(51.6 \%)$ with genu valgus (right $64.5 \%$, left $74.2 \%$ ) right hindfoot valgus $(64.5 \%)$ and left varus $(71.0 \%)$, and a reduction in the ankle angle $(100 \%)$, discharge weight of the right foot and bilateral forefoot. It was observed a significant correlation between changes in anteriorized body, flexed knee and reduction in the ankle angle to the weight load of bilateral forefoot, and pelvic retroversion with the weight load of his right foot. Conclusion: Patients with tropical spastic paraparesis have significant postural changes that alter their weight discharge.
\end{abstract}

Keywords: HTLV-1. Myelopathy; HAM/TSP; Postural assessment; Baropodometry. 


\section{INTRODUCTION}

Human T-cell lymphotrophic virus (HTLV-1) was the first retrovirus-associated disease in human being mainly associated with adult T-cell leukemia/lymphoma (ATLL) and tropical spastic paraparesis/HTLV-1-associated myelopathy (HAM/TSP). ${ }^{(1,2,3)}$ With regard to HTLV type 2, although there are no clear indications associating it with well-defined clinical manifestations, there is evidence that suggests its association with a clinical condition similar to HAM/TSP. ${ }^{(4)}$

It is estimated that 15 to 20 million people are infected with HTLV-1 in the world, however, approximately 95\% remain asymptomatic. Japan, the Caribbean, Central and South America, Equatorial Africa, Middle East and Melanesia are the main endemic areas, but prevalence in these areas are not uniform, varying from one city to another. This virus may be transmitted in three ways: sex, blood, by sharing needles and/or contaminated needles or blood transfusion, and vertical transmission, from mother to child, mainly through breastfeeding. ${ }^{(5)}$

In Brazil, most recent data suggest that the introduction of HTLV-1 was due to African immigration, and its estimates, based on prevalence, point to approximately 2.5 million infected people, in which the Brazilian city of Salvador has highest prevalence.in the country. A based population study in this city demonstrated a seroprevalence of approximately $1.8 \%$ significantly increasing with age and especially in females, affecting $9 \%$ of women over the age of 51 years. ${ }^{(6)}$

The HTLV-1-associated myelopathy or tropical spastic paraparesis (HAM/TSP) is characterized as a demyelinating, slow and progressive chronic inflammatory disease of the central nervous system. ${ }^{(7)}$ The first manifestations of disease occur in the fourth decade of life, with a ratio of $2: 1$ female to male. ${ }^{(6)}$ The virus affects the spinal cord determining the appearance of severe clinical syndrome due to motor disabilities affecting the lower limbs and lumbar spine, together with the associated autonomic dysfunction. In the predominant clinical condition of HAM/TSP, biomechanical, sensory and functional alterations are observed, characterized by the reduction in muscle strength of the pelvic girdle and lower limbs, low lumbar pain, gait disturbances, spastic hypertonia, muscle shortening and joint hypomobility, which predispose individuals to abnormal posture. (7,8,9) $^{2}$

In view of this context and due to the lack of studies with an objective postural assessment of individuals with HAM/TSP, it is necessary to describe and correlate postural deviations and the type of predominant weight load. 


\section{MATERIALS AND METHODS}

This is a cross-sectional descriptive study, conducted at the Center for HTLV at the Escola Bahiana de Medicina e Saúde Pública, located in the city of Salvador, Bahia. An interdisciplinary project including medical care, laboratory diagnosis, psychological assistance and physiotherapy is being carried out in this center. Data collection was conducted in the reference population from June to November 2009. The present study was approved by the Research Ethics Committee of the Fundação Bahiana para o Desenvolvimento das Ciências under protocol No 74/2008 on 25 September 2008. The diagnosis of HTLV-I infection was performed using ELISA (Cambridge Biotech Corp., Worcester, MA) and was confirmed by Western Blot analysis (HTLV blot 2.4, Genelab, Singapore).

Seropositive individuals for HTLV-1 and those who showed clinical condition compatible with HAM/TSP and agreed to sign the term of free and informed consent were included in the study. Patients who presented other disorders that compromised the definition of postural profile of patients with HAM/TSP such as rheumatic diseases, other neurological disorders, peripheral vestibular syndrome and patients unable to remain in standing position without assistance, were excluded from the study.

The selected individuals underwent an evaluation of orthostatic posture using the twodimensional software for Postural Assessment $\left(\mathrm{SAPO}^{\circledR}\right)$ version 0.67. ${ }^{(10)}$ Based on clinical relevance, scientific basis and methodological feasibility, the marking points and measurements for postural assessment were selected. To highlight those anatomical points, semi-polystyrene spheres $(25 \mathrm{~mm})$, whose central diameter was fixed with red adhesive tape, were used. A 10-centimeter ruler was fixed to the arms of the participants for later calibration of the image in the program. Anatomical location of the selected points was performed by palpation.

The height and weight of individuals were measured using an anthropometric mechanical scale Welmy brand (Santa Barbara D'Oeste), duly calibrated, and the body mass index (BMI) was calculated.

To obtain the photographs, a digital camera was used (Olympus Imaging Corporation D-535, made in China, with resolution of 3.2 megapixels) and it was placed perpendicular at a distance of 3 meters from the individual and at half the individual's height by using a tripod. The volunteers of the study were instructed to wear a minimum of clothing and to be barefoot. The women wore shorts and brassiere and the men wore only shorts to enable visualization of 
the body segments. The privacy of the participant during the assessment was sheltered in a closed room, and only the researchers of the study had access.

First the photographs were taken of the whole body of the individual in the following four views: anterior and posterior frontal view, right and left side view. To ensure the same base of support in all the views, the contour of the feet were made using white chalk on a black rubber mat with elbows flexed at 90 degrees, feet slightly open and Frankfurt Plane parallel to the ground. The procedure was performed after an interval of five seconds for proper positioning of the individual and during apnea after inspiration.

The photographs were transferred to a computer and calibrated. Through the selected marking points, the joint angles were analyzed.

Considering that the study population was composed of individuals with a paraparesis, affecting predominantly the lower limbs, measurements were focused on that region, not discarding the possibility of interference from deviations in the other body segments. Therefore, the angular measurements selected for the study were based on the protocol of markings of the anatomical points of SAPO ${ }^{\circledR}{ }^{(10)}$ (Figure 1) 
Figure 1 - Articular angles

\section{Anterior view}
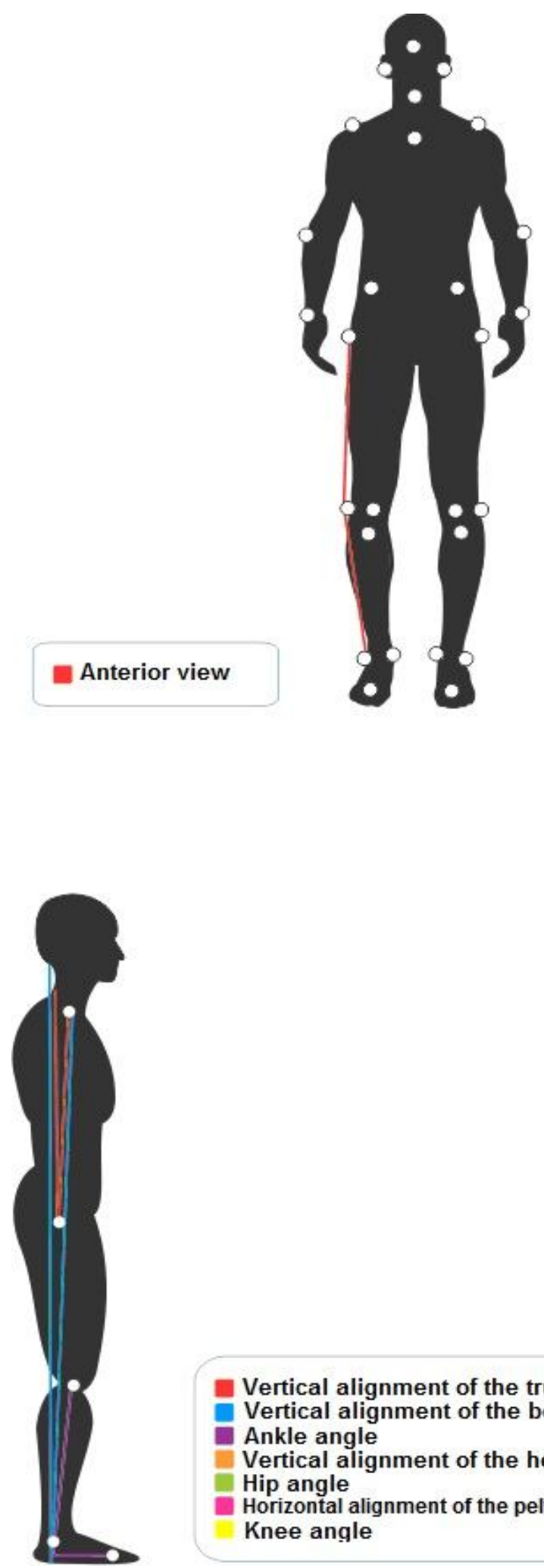

Vertical alignment of the trunk Vertical alignment of the body

Ankle angle

Vertical alignment of the head

Hip angle

Horizontal alignment of the pelvis

Knee angle

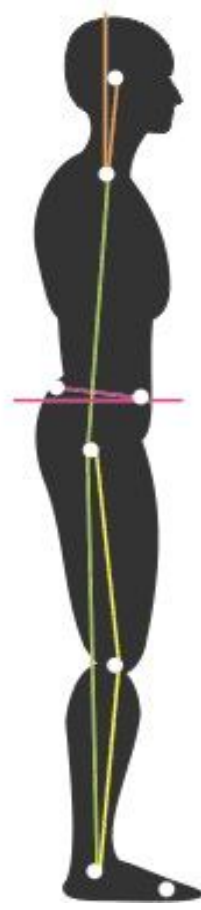


The Foot Work electronic baropodometer composed of a modular platform, which was acquired from the importer and distributor of the French company AM3-IST in Brazil, was used in the second stage. The quasi-static analysis tool provides maximum pressure and mean, anterior and posterior and right and left division and by area, 3D image, left and right center of mass, projection of the center of gravity and point of maximum pressure. The procedure was performed with subjects positioned as previously mentioned in postural analysis and to record these values the participants remained in standing positions for 20 seconds. The same position was repeated 3 times to make the means between the above-mentioned measurements available.

Among the variables of this research, independent postural changes are obtained, such as the dependent variable of weight load, as well as the co-variables, such as age, BMI, period of illness of the individuals, gender and race. The data were analyzed descriptively in proportions and quantitatively in means with standard deviations. Analyses were performed to assess the relationship of weight load with postural changes by Pearson or Spearman correlation tests, depending on the distribution of the variables, using SPSS (Statistical Package for the Social Sciences) version 14.0, and an alpha value of 5\% was accepted as significant $(\alpha \leq 0.05)$.

\section{STATEMENT OF ETHICS}

We certify that all institutional and governmental regulations on the ethical use of human volunteers were followed during the course of this research. Most notable is the absence of risk and discomfort to the participant's health, respect for volunteers in the study and confidentiality of information as data access was granted only to researchers.

\section{RESULTS}

The sample were composed of 49 individuals with HTLV-1-associated myelopathy (HAM/TSP) from which eight $(16.3 \%)$ were excluded due to the inability to maintain the standing position, 5 (10.2\%) were excluded for presenting rheumatic or orthopedic diseases, 4 $(8.1 \%)$ because they had other neurological afflictions and $1(2.0 \%)$ due to peripheral vestibular dysfunction. Thus, the final sample consisted of 31 patients, 54.8\% were female, with a predominance of African descent representing $58.1 \%$ of the population (Table 1 ).

Brazilian Journal of Medicine and Human Health, Salvador, jan. 2013; 1(1): 19-33. 
Table 1 - Characterization sample of individuals with TSP/HAM of Center for HTLV, second sex and race. Salvador - Bahia, Brazil, 2009

\begin{tabular}{llr}
\hline \multicolumn{1}{c}{ Variables } & n & $(\%)$ \\
\hline Gender & & \\
Female & 17 & $\mathbf{5 4 , 8}$ \\
Male & 14 & 45,2 \\
Race & & \\
African & 18 & $\mathbf{5 8 , 1}$ \\
descent & & \\
White & 3 & 9,7 \\
Brown & 8 & 25,8 \\
Índian & 2 & 6,5 \\
\hline
\end{tabular}

Mean age was of 52.8 years $( \pm 8.8)$ and minimum age was of 33 years and maximum of 71 years. It was found that the mean BMI was $24( \pm 4.8)$ and the mean period of disease was 7.4 years $( \pm 8.3)($ Table 2$)$.

Table 2 - Characterization sample of individuals with TSP/HAM of Center for HTLV, second the age, BMI and period of disease. Salvador - Bahia, Brazil, 2009

\begin{tabular}{lc}
\hline \multicolumn{1}{c}{ Variables } & Mean $\left(\right.$ SD $\left.^{*}\right)$ \\
\hline Age (years) & $52,8 \pm 8,8$ \\
BMI * & $24,0 \pm 4,8$ \\
Period of disease & $7,4 \pm 8,3$ \\
\hline \multicolumn{2}{r}{$*$ Standard deviation } \\
* BMI = body mass index $\left(\mathrm{kg} / \mathrm{cm}^{2}\right)$
\end{tabular}

In Table 3, considering the most prevalent postural changes, the orthostatic posture of the patient's profile is characterized by an anteriorized position of the head $(80.6 \%)$, trunk displaced posteriorly (64.5\%), anteriorized body (96.8\%), hip extension (77.4\%), pelvic retroversion (61.3\%), flexed knee (51.6\%) with genu valgus (right 64.5\%, left $74.2 \%$ ) right hindfoot valgus (64.5\%) and left varus (71.0\%), and a reduction in the ankle angle (100\%). 
Table 3 - Description of the postural deviations predominant postural assessment of individuals with TSP/HAM of Center for HTLV. Salvador - Bahia, Brazil, 2009

\begin{tabular}{|c|c|c|}
\hline & $\mathbf{N}(\%)$ & Mean (SD) \\
\hline \multicolumn{3}{|l|}{ Anterior View } \\
\hline Knee Valgus R* & $20(64,5)$ & $4,3 \pm 3,1$ \\
\hline Knee Valgus L* & $23(74,2)$ & $3,6 \pm 2,9$ \\
\hline \multicolumn{3}{|l|}{ Posterior View } \\
\hline Hindfoot Valgus R* & $20(64,5)$ & $9,8 \pm 9,1$ \\
\hline Hindfoot Varus L* & $22(71,0)$ & $5,0 \pm 3,2$ \\
\hline \multicolumn{3}{|l|}{ Right Lateral View } \\
\hline Anteriorized head & $24(77,4)$ & $14,6 \pm 8,6$ \\
\hline $\begin{array}{l}\text { Trunk displaced } \\
\text { posteriorly }\end{array}$ & $20(64,5)$ & $4,7 \pm 2,3$ \\
\hline Hip Extension & $24(77,4)$ & $8,7 \pm 5,7$ \\
\hline Anteriorized body & $30(96,8)$ & $2,3 \pm 1,3$ \\
\hline Pelvic Retroversion & $19(61,3)$ & $12,8 \pm 4,1$ \\
\hline Flexed Knee & $16(51,6)$ & $15,4 \pm 9,7$ \\
\hline Ankle Angle & $31(100)$ & $82,1 \pm 5,8$ \\
\hline \multicolumn{3}{|l|}{ Left Lateral View } \\
\hline Anteriorized head & $25(80,6)$ & $16,4 \pm 10,3$ \\
\hline $\begin{array}{ll}\text { Trunk } & \text { displaced } \\
\text { posteriorly } & \end{array}$ & $20(64,5)$ & $5,1 \pm 2,5$ \\
\hline Hip Extension & $22(71,0)$ & $8,7 \pm 5,8$ \\
\hline Anteriorized body & $24(77,4)$ & $2,7 \pm 1,8$ \\
\hline Pelvic Retroversion & $17(54,8)$ & $11,8 \pm 4,5$ \\
\hline Flexed Knee & $16(51,6)$ & $15,6 \pm 10,9$ \\
\hline Ankle Angle & $31(100)$ & $82,6 \pm 6,8$ \\
\hline
\end{tabular}

$* \mathrm{R} / \mathrm{L}:$ Right/Left

With regard to the baropodometric analysis (Table 4), it was found that there was a predominance in the weight load of the right foot with a mean of $53.4(+6.4)$ and bilateral support on the forefoot region with a mean of $51.0( \pm 8.8)$. 
Table 4 - Description of variables baropodometric evaluation of individuals with TSP/HAM of Center for HTLV. Salvador - Bahia, Brazil, 2009

\begin{tabular}{|c|c|c|}
\hline \multicolumn{2}{|c|}{ Variables } & Mean (SD) \\
\hline \multicolumn{2}{|c|}{ W.L. ** Foot L* } & $46,5 \pm 6,4$ \\
\hline \multicolumn{2}{|c|}{ W.L. Foot R* } & $53,4 \pm 6,4$ \\
\hline W.L. & Bilateral & $48,9 \pm 8,8$ \\
\hline \multicolumn{3}{|c|}{ Hindfoot } \\
\hline W.L. & Bilateral & $51,0 \pm 8,8$ \\
\hline \multicolumn{3}{|c|}{ Forefoot } \\
\hline
\end{tabular}

Considering the predominant postural changes that correlate with weight load, there was statistical significance between the weight load on the right foot and pelvic retroversion ( $\mathrm{r}$ $=-0.4)$ in the right lateral view. There was a linear correlation between the weight load of bilateral forefoot between the ankle angle $(r=-0.4)$ in the right lateral view, anteriorized body $(\mathrm{r}=0.4)$, flexed knee $(\mathrm{r}=0.4)$ and ankle angle $(\mathrm{r}=-0.5)$ in the left lateral view (Table 5).

Table 5 - Linear correlation between the postural deviations and the weight load. Salvador - Bahia, Brazil, 2009.

\begin{tabular}{lcc}
\hline & Right Foot & Bilateral Forefoot \\
\hline Anterior View & $r$ & $r$ \\
$\quad$ Right Knee Valgus & $0,4 * *$ & $-0,1 *$ \\
Left Knee Valgus & - & $-0,2 *$ \\
Posterior View & & \\
Right Hindfoot Valgus & $-0,3 * *$ & $0,1 *$ \\
Left Hindfoot Varus & - & $-0,2 *$ \\
Right Lateral View & & \\
Anteriorized head & $0,1 * *$ & $0,1 * *$ \\
Trunk displaced posteriorly & $-0,2 * *$ & $0,0 * *$ \\
Hip Extension & $0,3 * *$ & $-0,0 * *$ \\
Anteriorized body & $0,2 * *$ & $0,0 * *$
\end{tabular}


Pelvic Retroversion

Flexed Knee

Ankle Angle

Left Lateral View

Anteriorized head

Trunk displaced posteriorly

Hip Extension

Anteriorized body

Pelvic Retroversion

Flexed Knee

Ankle Angle
$-0,4 * *$
$0,2 * *$
$0,3 * *$
$0,3 * *$
$0,2 * *$
$-0,4 *$

$\begin{array}{cc}-0,0 * * \\ - & 0,0 * \\ - & -0,1 * * \\ - & \mathbf{0 , 4} * \\ - & 0,0 * * \\ - & \mathbf{0 , 4} * * \\ - & \mathbf{- 0 , 5} * *\end{array}$

\section{$*$ Pearson ** Spearman Significance $\alpha \leq \mathbf{0 , 0 5}$}

\section{DISCUSSION}

Observing the postural attitude of patients with HTLV-1-associated myelopathy/tropical spastic paraparesis (HAM/TSP), a higher prevalence of postural deviations was found characterized by the anteriorization of the head and body, trunk displaced posteriorly, pelvic retroversion of hip extension, knee flexion with the presence of genu valgum, right hindfoot valgus and left varus and a reduction in ankle angle. It was observed that this posture caused an increase in weight load on the right foot and bilateral forefoot. But the changes of anteriorization of the body, knee flexion and reduction of the ankle angle showed a significant correlation with load on the bilateral forefoot and pelvic retroversion with load on the right foot.

From a neurological disease, postural deviations found in the sample can be considered consequences of neurologic compromise of these individuals, such as weakness and spastic hypertonia of lower limbs. This compromise has possibly modified orthostatic posture causing alterations in the weight load. In agreement with the results, studies show that changes in postural alignment are usually characteristics of a patient with neurological problems and it causes changes in the disposition of a body segment over another or the alignment of the center of mass from the base of support. ${ }^{(11,12)}$

Lesions in the central nervous system (CNS) affect static postural control due to the modification of the center of gravity, as a result of the abnormal postural pattern that is a characteristic of spasticity. Since patients with spastic hypertonia present impairment of 
reciprocal innervation, in this situation, there is excessive and stereotyped activity that prevents tonic adjustments for postural control. ${ }^{(13)}$

Within this context, in the present study, the patient with TSP /HAM has poor alignment of body segments, which may be caused by the above-mentioned characteristics. Good joint alignments, strong and flexible muscles, which easily adapt to environmental changes, are needed to maintain correct posture. The complexity of the standing position, as well as its various factors and variables that influence human equilibrium directly and indirectly, such as mechanical factors, anthropometric and neuromuscular factors, give emphasis to the control of static posture. Postural control refers to an individual's ability to maintain stability of the body and body segments in response to forces that threaten to disrupt structural balance. ${ }^{(14)}$ To maintain this balance, basic postural tonus is needed, which, in turn, is considered an ascending segmental organization, which progressively installs itself in accordance with the needs of static, in which each segment is in equilibrium on the lower segment. Furthermore, related to the pelvic girdle and lower limbs, the position of those are controlled by the muscle tonus that attach to them. But the joint surfaces also impose their mechanical axes that drive the movements related to these bone structures. However, because of this dual control, a change in tonus, even if minimal, triggers a cascade of changes in posture of the whole body. ${ }^{(15,16)}$ This explains the mechanism of postural changes found in this study, in the pelvicpodal structure of these individuals suffering from TSP/ HAM.

The foot system is an important tool of the CNS in controlling posture because it uses the ascending motor pathways, which receive information from the feet, to control the positions of the feet and body and to coordinate postural movements in relation to the external environment. ${ }^{(17)}$ The adaptation of the foot to the lower limb and pelvic girdle is a fundamental physiology to understanding the static problems in both the ascending and descending systems. ${ }^{(16)}$ An important system in postural control is the proprioceptive system, formed by the muscle spindles, tendon organs and joint receptors, which provide sensory information for effective maintenance of posture. Variations in the base or in the static of the body usually involve postural deviations, which change the center of pressure to a relative base of support. As observed in this study, individuals with myelopathy have spasticity and hypertonia of specific muscle groups of the lower limbs, which allows a consequent adjustment of the plantar support. However, changes may occur in reverse, in which changes in the feet and load modify ascending posture. In accordance, a study reports that the deformations of the feet can be a cause or consequence of static problems, whereas support of

Brazilian Journal of Medicine and Human Health, Salvador, jan. 2013; 1(1): 19-33 
feet to the ground affects statics and there is no good static without good support. After all, any deformation of the feet will require an adaptation of the postural system. ${ }^{(15)}$

When examining the possible postural compensations of the individuals studied, one may observe that in an endeavor to maintain orthostasis, the patient unloads weight on the forefoot area bilaterally, especially on the right foot, resulting in postural adjustments since the body is displaced anteriorly, knees flexed, with a consequent reduction in the tibiotarsal angle as well as pelvic retroversion from static imbalance. These deviations may have been triggered by the inability of the individuals to maintain themselves against gravity as a consequence of muscle weakness on the part of the anti-gravity muscles in the posterior chain, presence of spasticity and shortening of muscles involved in maintaining the alignment of the hip, knee and ankle. In the pathology in question, all the muscle groups can be affected especially the flexor and adductor muscles of the lower limbs. ${ }^{(7,18)}$

In this study, the proportion that becomes more severe the effect of HAM/TSP in terms of postural misalignment, the greater the weight load in a particular area of the foot. Observing the most prevalent loads with statistical significance, there is greater support on the forefoot bilaterally. This finding corroborates the findings in a study in which patients with spastic hemiplegia after cerebrovascular accident (CVA) showed a higher peak of plantar pressure on the bilateral forefoot region and a tendency for greater weight load on the nonaffected limb. ${ }^{(19)}$ In disagreement with these findings, another study with a population of hemiplegic patients, also as a result of CVA, a smaller surface of plantar support on hemiplegic side compared with the non-affected hemisphere was found, with a point of more pressure on the hindfoot region. ${ }^{(20)}$

These authors explain that the distribution of plantar pressure in normal individuals present morphological features and similar plantar pressure on both feet. Whereas patients who have some motor impairment as a result of neurological impairment, the pressure distribution between the feet occurs in different ways. These findings may be justified due to the following factors: reduction in motor action of the lower limbs, disturbance in muscle coordination, sensory impairment, imbalance and insufficient weight transfer resulting in limited mobility. ${ }^{(19)}$

These tendencies of weight load on a particular limb or region of the foot may be a compensatory mechanism for the individuals to maintain their orthostatic postural balance. Any imbalance, be it segmental or joint imbalance, shall be compensated in the same plane by an equal imbalance but in the opposite direction. According to the anatomical features, the 
compensation may occur on one or more segments, on one or more joints, in one or more planes. $^{(15)}$

Considering the different mechanisms of postural adaptation observed in individuals in whom control is poor, the inability of the individuals to maintain themselves against gravity due to their clinical debilitating condition promotes the postural misalignment with subsequent alterations in weight load.

As a limitation of this research, it is noteworthy that the postural assessment used is a two-dimensional method, which is not adjusted for the center-of-mass oscillations. However, it is considered to be efficient, objective and detailed. Moreover, the photographs were acquired during apnea after inspiration, reducing the influence of center-of-mass oscillations. The lack of studies related to the subject is considered another limitation of the study.

Further studies may be developed to seek the causes of postural misalignments and plantar weight load as well as evaluate the results of postural approaches focused on the deviations of these individuals.

\section{CONCLUSION}

Individuals with HAM/TSP show abnormal postural characteristics of a neurological involvement, which are correlated with weight load.

Since the postural and baropodometric assessment is a relevant factor in the functional diagnosis and pre-planning of a comprehensive physical therapy rehabilitation program, the findings become fundamental to the understanding of postural changes in the profile of the patient, with the purpose of implementing approaches to maintenance, muscle recovery, and range of joint motion.

\section{ACKNOWLEDGEMENTS}

We thank Mrs. Luciana Moreira for assistance in data collection and Mr. Noilson Lázaro Gonçalves for technical assistance.

This research received financial support from the Scholarship Program for Scientific Initiation of the Bahia Foundation for Science Development - Year 2008/2009, taking stock as the authors Edelvita Fernanda Duarte Cunha and Naiane Araújo Patrício and Brazilian Reseach Council (CNPq). 


\section{REFERENCES}

1. Poiesz BJ, Ruscetti FW, Gazdar AF, Bunn PA, Minna JA, Gallo RC. Detection and isolation of type $\mathrm{C}$ retrovirus particles from fresh and cultured lymphocytes of a patient with cutaneous T-cell lymphoma. Proceedings of the National Academy of Sciences of the USA. 1980;77:7415-7419.

2. Gessain A, Barin F, Vernant JC, Gout O, Maurs L, Calender A et al. Antibodies to human T. lymphotropic virus type-I in patients with tropical spastic paraparesis. Lancet. 1985; 2:407410.

3. Osame M, Usuku K, Izumo S, Ijichi N, Amitani H, Igata A et al. HTLV-I associated myelopathy, a new clinical entity. Lancet.1986;1:1031-1032.

4. Araujo A, Hall WW. Human T-lymphotropic virus type II and neurological disease. Ann Neurol. 2004; 56:10-19.

5. Hella C, Shepperd S, Khumalo NP, Taylor GP. The prevalence of human T-cell lymphotropic virus type 1 in the general population is unknown. AIDS Rev. 2009;11(4):205214.

6. Galvão-Castro B, Alcântra Júnior LC, Grassi MFR, Mota-Miranda ACA, Queiroz ATL, Rego FFA. Epidemiologia e origem do HTLV-I em Salvador Estado da Bahia: A cidade com a mais elevada prevalência desta infecção no Brasil. Gaz méd Bahia 2009;79(1):3-10.

7. Ribas JGR, Melo GCN. Mielopatia associada ao vírus linfotrópico humano de células T do tipo 1 (HTLV-1). Rev Soc Bras Med Trop. 2002; 34(5):377-384.

8. Macêdo MC, Andrade ASF, Figuerôa FLS. Avaliação das alterações biomecânicas, funcionais e sensoriais em pacientes portadores do HTLV-I associado à HAM/TSP: Uma visão fisioterapêutica. Rev Bras Neurol Psiquiatri. 2002; 1(6):12-21.

9. Tavares IR, Franzoi AC, Araújo AQC. Low-back pain in HTLV-I-associated myelopathy/tropical spastic paraparesis: nociceptive or neuropathic? Spinal Cord. 2009; 48: 134-137.

10. Duarte M, Puig EM, Freitas AZ, Ferreira EA. Software para Avaliação Postural. São Paulo: USP; 2007; [Access 16 March 2008]. Available:

$<$ http://sapo.incubadora.fapesp.br/portal>.

11. Shumway-Cook A, Woollacott MH. Controle Postural Anormal. IN: Shumway-Cook A, Woollacott MH. Controle Motor-Teoria e aplicações práticas. 2a ed. Barueri: Manole; 2003. p. 233-254.

12. Mochizuki L, Amadio AC. As informações sensoriais para o controle postural. Rev Fisioter Mov. 2006; 19: 11-18.

13. Umphred DA, El-Din D. Fisioterapia Neurológica. 4ª ed. Barueri: Manole; 2004. 
14. Magee DJ. Avaliação Musculoesquelética. $4^{a}$ ed. Barueri: Manole; 2005.

15. Bienfat M. Desequilíbrios Estáticos. 3ª ed. São Paulo: Summus; 1995.

16. Gagey PM, Weber B. Posturologia: regulação e distúrbios da posição ortostática. $2^{\mathrm{a}}$ ed. São Paulo: Manole; 2000.

17. Horak FB, Shupert CL. Função do Sistema Vestibular no Controle Postural. In: Herdman SJ. Reabilitação Vestibular. 2a ed. São Paulo: Manole; 2002.

18. Franzoi AC, Araújo AQC. Disability and determinants of gait performance in tropical spastic paraparesis/HTLV-I associated myelopathy (HAM/TSP). Spinal Cord. 2007; 45: 6468 .

19. Schuster RC, Zadra K, Mathias L, Polese JC, Mazzola D, Sander I et. al. Análise da pressão plantar em pacientes com acidente vascular encefálico. Rev Neurocienc. 2008; 16(3): 179-183.

20. Boza RG, Duarte EO, Belmonte EM, Marco EN, Muniesa JMP, Sánchez MT et al. Estudio baropodometrico en el hemipléjico vascular: relación con la discapacidad, equilibrio y capacidad de marcha. Rehabilitación (Madr). 2007; 41(1): 3-9. 